\title{
Effects of Different Fertilizer Rates on Total Polyphenols and Catechins of Selected Clones of Green Tea (Camellia sinensis L. [O] Kuntze)
}

\author{
Evans Kenanda Okemwa ${ }^{1, *}$, Koskei Kipkoech Silvanuss ${ }^{2}$ \\ ${ }^{1}$ Department of Research and Extension, Kisii University, Kisii, Kenya \\ ${ }^{2}$ Department of Chemistry, School of Pure and Applied Sciences, Kisii University, Kisii, Kenya \\ Email address: \\ ekenanda@kisiiuniversity.ac.ke (E. K. Okemwa) \\ ${ }^{*}$ Corresponding author
}

To cite this article:

Evans Kenanda Okemwa, Koskei Kipkoech Silvanuss. Effects of Different Fertilizer Rates on Total Polyphenols and Catechins of Selected Clones of Green Tea (Camellia Sinensis L. [O] Kuntze). World Journal of Applied Chemistry. Vol. 5, No. 2, 2020, pp. 13-19. doi: 10.11648/j.wjac.20200502.11

Received: June 4, 2020; Accepted: June 18, 2020; Published: June 28, 2020

\begin{abstract}
Application of inorganic NPK (nitrogen: phosphorus: potassium) fertilizers on tea (Camellia sinensis) has been common among small-scale tea farmers to increase production. However, the cost of fertilizers has been increasing and reducing their net returns. Fertilizers applications also affect the quality of the crop which is mainly dictated by the total polyphenols and catechins; these metabolites are responsible for its anti-oxidant activity, taste and aroma. The focus of this work was on the effect of varying NPK fertilizer application rate on the levels of total polyphenols and catechins of green tea made from three tea cultivars and development of an optimum NPK fertilizer application rate. Samples of three varieties, AHP S15/10, TRFK 6/8 (Tea Research Foundation of Kenya), and BBK 35, were collected from Mettarora, Arroket and Monire tea estates within Sotik highlands. Randomized complete block design sampling was used and sampling was done 6-8 weeks after application of the treatment. The fertilizer used was inorganic plain NPK fertilizer and NPK fertilizer supplemented with Molybdenum. The experimental treatments consisted of six treatments made up NPK 25:5:5; at 0,75, 150, 225, 300, and 375 $\mathrm{kg} \mathrm{N} / \mathrm{ha} /$ year. The collected samples were processed as non-aerated green CTC (Cut, Tear and Curl) teas at the miniature processing factory unit at Kenya Agricultural and Livestock Research Organisation - Tea Research Institute (KALRO-TRI) at Kericho County. Processed tea samples were milled and chemical analysis done to quantify the levels of biochemicals in the samples. Data obtained were subjected to Analysis of Variance (ANOVA) and mean separation was done using the least significant difference test at $p \leq 0.05$. TRFK $6 / 8$ was found to have the highest mean percentage total polyphenols of 25.90 followed by BBK 35 with a mean percentage total polyphenols of 25.75. AHP S15/10 recorded the least mean percentage total polyphenols of 23.70. A similar trend was observed in the mean percentages of catechins with TRFK 6/8, BBK 35 and AHP S $15 / 10$ recording $20.7 \%, 18.87 \% 18.46 \%$ respectively. Hence, use of optimum NPK fertilizer application rate specific to each clone supplemented with Molybdenum boosts the levels of polyphenols and catechins in green tea.
\end{abstract}

Keywords: Cultivars, Polyphenols, Catechins, Fertilizers, Anti-oxidant Activity

\section{Introduction}

Application of fertilizers is an important part of the normal intensive production of tea [1]. Optimum fertilizer application in association with other appropriate cultural practises produces high yields [2]. As increasing levels of fertilizer application leads to increased yield, concerns arise as to whether the quality of tea is affected. The effect produced can be measured either by chemical analysis for the flavouring compounds or subjectively by Taster's report [3]. Quantification of bio-chemicals in this report is done through laboratory analyses [3]. The aim of this study, therefore, was to investigate fertilizer uptake in different varieties of tea in Kenya and determine its effects on tea quality parameters variations.

Studies have shown that, after a period of time, there is a reduction of nutrients in the soil under tea plantation either 
through utilization by tea plants or through leaching during a rainy season [2]. Loss of nutrients in the soil leads to the reduction in production and also affects quality tea parameters such as total polyphenols levels [4, 5, 6] Application of inorganic fertilizers has remained to be the only way to enhance the production of tea leaves and also the quality parameters, e.g. Catechins [7]. From previous studies, it has been established that application of fertilizers increases the nutrients in the soil which are in turn used by tea plants [8]. However, with the rising cost of inorganic fertilizer, there is need to determine an optimum fertilizer application rate to reduce the cost of production and at the same time sustain the quality. This project involved analysis of total polyphenols and Catechins from green tea applied with different rates of NPK fertilizers.

The quality of tea, as a drink, is largely determined by the presence or absence of chemical compounds, which are responsible for colour, briskness, brightness, strength and flavour in the infusion [9] Majority of the chemicals imparting quality are produced during processing of the tea leaves. Biogenesis of such precursors is influenced, on one hand by the genetic and environmental factors and on the other by the cultural practices adopted in the field as well as by the conditions of processing, which can be controlled though biochemical changes that start immediately after plucking. Polyphenols work out to about $15-20 \%$ in the black tea, and it comprises the catechins fractions [10]. Compared to black tea, green tea has a higher content of polyphenols, almost around $25-30 \%$ on the dry weight basis. All the above constituents may vary in their content according to the type of tea plants, environment, agronomic practices, pest \& disease incidence and manufacturing practices [11]. Depending on the type of tea, which is basically due to different ways of processing, tea product may contain different chemicals with varied concentrations [12].

Flavanol, flavonols, glycosides, polyphenolic acids and depsides put together are referred to as total polyphenols and make up about $30 \%$ of the dry weight in a tea shoot. Flavanols or Catechins are the major compounds that are oxidizable in the tea leaf. (-) Epigallocatechin (EGC) and (-) epigallocatechin gallate (EGCG) are the predominant catechins present in tea leaf. There are four types of Catechins; Epicatechin, epicatechin-3-gallate, epigallocatechin, epigallocatechin-3-gallate (Figure 1) [13]. The Catechins play a significant role during oxidation ([14]. Tea polyphenols include phenolic acids and flavonoids, which may account for up to $30 \%$ of the dry weight in fresh green leaves. Flavonols are phenol derivatives synthesized in substantial amounts and widely distributed among plants. Other bio-chemicals such as the arubigins and the aflavins are present in black tea [15].

Young tea shoots are extremely rich in many biochemicals compared to other parts of the tea plant [16]. The levels of those bio-chemicals vary depending on a number of factors such as the type of clone, season of plucking, compositing of soil, fertilizer rates applied and method of processing among other factors.
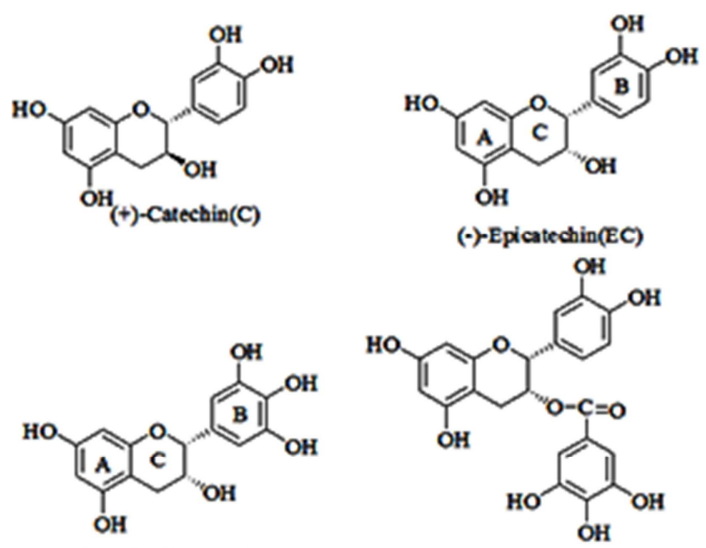

(-)-Epicatechin gallate (ECO)<smiles>O=C(O[C@H]1Cc2c(O)cc(O)cc2O[C@H]1c1cc(O)c(O)c(O)c1)c1cc(O)c(O)c(O)c1</smiles>

Figure 1. Types of Catechins.

EGCG has been found to be in high concentration in green tea. It is the most active and most researched of tea ingredients. The beneficial health effect is that, it is effective in neutralizing free radicals than vitamin $\mathrm{C}$ and twenty five (25) times more powerful than vitamin E [17].

\section{Materials and Methods}

\subsection{Sample Collection}

The samples were collected from three different areas within Sotik highlands; Mettarora, Arroket and Monieri and the varieties collected included; AHP S15/10, TRFK 6/8, and BBK 35 respectively. These samples were plucked from different fields of different spacing and sizes. Arroket samples were plucked from field number 13, of size 39 (13' x $\left.3^{\prime}\right)$ plants per plot excluding guard rows, with a spacing of $1.22 \mathrm{~m}$ x $0.76 \mathrm{~m}$ (4'x 2.5') 10766 plants/ ha. Monieri samples were plucked from field number 38 , of size $45\left(15^{\prime} \times 3^{\prime}\right)$ plants per plot excluding guard rows, with a spacing of $1.22 \mathrm{~m}$ x $0.76 \mathrm{~m}\left(4^{\prime} \times 2.5^{\prime}\right) 10766$ plants/ ha. Mettarora samples were plucked from field number 26 , of size 45 (15' $\mathrm{x}$ $\left.3^{\prime}\right)$ plants per plot excluding guard rows, with a spacing of $1.22 \mathrm{~m} \times 0.76 \mathrm{~m}$ (4' $\left.4^{\prime} \times 2.5^{\prime}\right) 10766$ plants/ ha. The experimental treatments consisting of six treatments made up as follows: NPK 25:5:5; at 0, 75, 150, 225, 300, and $375 \mathrm{~kg}$ $\mathrm{N} /$ ha/year. Sampling was done 6-8 weeks after application of the treatment. The samples were processed as non-aerated green CTC teas at the miniature processing factory unit at KALRO-TRI, Kericho.

\subsection{Preparation of Non-aerated Green Tea}

After 6 weeks of application of NPK fertilizers, two leaves 
and a bud, the crop shoots normally harvested for manufacturing [18], were plucked and put in a polyethene bag to weigh approximately 50 grams and labelled. The collected tea leaves were steamed at $90^{\circ} \mathrm{C}$ for 1 minute. This was to kill enzyme polyphenol oxidase which oxidises polyphenols and catechins to thearubigins and theaflavins. The tea sample was then crushed in a CTC machine and dried in a fluid bed drier for 30 minutes to obtain non-aerated green tea.

\subsection{Colorimetric Analysis of Total Polyphenols}

\subsubsection{Extraction of Polyphenols}

Extraction and analysis of Total Polyphenols (TP) was done according to ISO procedures [3]. Polyphenols were extracted with $70 \%$ methanol from a tea portion of finely ground leaf tea at $70^{\circ} \mathrm{C}$. The polyphenols in the extract were determined calorimetrically using Folin-Ciocalteu phenol reagent. This reagent contained phosphor-tungstic acids as oxidants, which on reduction by readily oxidized phenolic hydroxyl groups, yielded a blue colour with a broad maximum absorption at $765 \mathrm{~nm}$. This was due to the formation of the so-called tungsten and molybdenum blues. The Folin-ciocalteu phenol reagent reacted with a wide range of polyphenol compounds and although the response could vary with individual components, a selection of Gallic acid as a calibration standard enabled useful total polyphenol data to be obtained.

\subsubsection{Analysis of Total Polyphenols}

Five standards labelled A, B, C, D and E, corresponding to approximately $10 \mu \mathrm{g}, 20 \mu \mathrm{g}, 30 \mu \mathrm{g}, 40 \mu \mathrm{g}, 50 \mu \mathrm{g}$ of anhydrous Gallic acid respectively were used. $0.2 \pm 0.01 \mathrm{~g}$ of the test samples were weighed into extraction tubes. $70 \%$ methanol/water extraction mixture contained in a dispenser was placed in the water bath set at $70^{\circ} \mathrm{C}$ and allowed at least 30 minutes for extraction mixture to equilibrate. The extraction tubes containing the samples were then placed in the water-bath set at $70^{\circ} \mathrm{C} .5 .0 \mathrm{~mL}$ of the hot methanol/water extraction mixture was dispensed into the extraction tubes, corked and mixed using a vortex mixer. The extraction tubes were heated in the water bath for 10 minutes and mixed on the vortex mixer after the 5 th and the 10th minute. The extraction tubes were removed from the water bath and allowed to cool to room temperature. Centrifugation of the tubes followed at $3500 \mathrm{rpm}$ for 10 minutes. The supernatant was carefully decanted into a graduated tube. Extraction was repeated, and the two extracts combined to make up to $10 \mathrm{ml}$ with methanol/water extraction mixture. $1 \mathrm{ml}$ of the sample extract was transferred into a one-mark $100 \mathrm{~mL}$ volumetric flask, and filled to the mark using distilled water. $1 \mathrm{~mL}$ of diluted sample extract was pipetted into a test tube, and then $5.0 \mathrm{~mL}$ of dilute Folin-Ciocalteu phenol reagents added and mixed. Within 3-8 minutes after the addition of FolinCiocalteu phenol reagent, $4.0 \mathrm{~mL}$ of sodium carbonate solution was pipetted into each test tube and mixed. The mixture was allowed to stand for $60 \mathrm{~min}$ at room temperature and absorbance measured in $10 \mathrm{~mm}$ path length cell against water on the spectrophotometer set at a wavelength of
$765 \mathrm{~nm}$. The total polyphenol content expressed as percentage by mass of the sample dry matter basis was calculated using the formula:-

$$
W T=\frac{(D \text { sample }-D \text { intercept }) \times V \text { sample } \times d \times 100}{\text { Sstd } \times \text { Msample } \times 1000 \times W D M, \text { sample }}
$$

Where;

WT -Percentage Total Polyphenols

D sample -optical density of the sample test solution

D intercept-optical density at the point of the best fit linear calibration

M sample -mass $(\mathrm{g})$ of the sample test portion

$\mathrm{V}$ sample -sample extraction volume in millilitres $(10 \mathrm{ml}$ of tea leaf extract)

D -dilution factor used prior to the calorimetric determination

WDM sample -is the dry matter

\subsection{HPLC Analysis of Catechins}

\subsubsection{Extraction of Catechins}

Extraction of Catechins was done according to the ISO procedures [3]. 2005.0.2 $\pm 0.01 \mathrm{~g}$ of the test samples were weighed into extraction tubes. $70 \%$ methanol/water $(\mathrm{v} / \mathrm{v})$ extraction mixture contained in a dispenser was placed in the water bath set at $70^{\circ} \mathrm{C}$ and allowed at least 30 minutes for extraction mixture to equilibrate. The extraction tubes containing the samples were then placed in the water-bath set at $70^{\circ} \mathrm{C} .5 .0 \mathrm{~mL}$ of the hot methanol/water extraction mixture was dispensed into the extraction tubes, corked and mixed using a vortex mixer. The extraction tubes were heated in the water bath for 10 minutes and mixed on the vortex mixer after the 5 th and the 10th minute. The extraction tubes were removed from the water bath and allowed to cool to room temperature $\left(24^{\circ} \mathrm{C}\right)$. Centrifugation of the tubes followed at $3500 \mathrm{rpm}$ for 10 minutes. The supernatant was carefully decanted into a graduated tube. Extraction was repeated and the two extracts combined to make up to $10 \mathrm{ml}$ with methanol/water extraction mixture.

\subsubsection{Analysis of Catechins}

High performance liquid chromatography (HPLC) analysis was done according to the procedure by ISO14502$2: 2005[3] .1 \mathrm{~mL}$ of sample was pipetted into a test tube and diluted to $5 \mathrm{~mL}$ with a stabilizing solution $(10 \%(\mathrm{v} / \mathrm{v})$ acetonitrile with $500 \mu \mathrm{g} / \mathrm{mL}$ of EDTA and $500 \mu \mathrm{g} / \mathrm{mL}$ ascorbic acid), filtered and loaded into $2 \mathrm{~mL}$ vials. HPLC fitted with an SPD-20 UV-Visible detector and $\mathrm{C}_{6}, 25 \mathrm{~cm} \times 4.6$ i.e. column was used for determination at $278 \mathrm{~nm}$. The solvent systems for gradient elution included: Mobile phase A (9:2:89 (v/v/v) Acetonitrile: Acetic acid: EDTA) and mobile phase B $(80: 2: 18(\mathrm{v} / \mathrm{v} / \mathrm{v})$ Acetonitrile: acetic acid: EDTA) at a flow rate of $1 \mathrm{~mL} / \mathrm{min}$. The column temperature was set at $35 \pm$ $0.5^{\circ} \mathrm{C}$ and the injection volume of $20 \mu \mathrm{L}$ used. The conditions for the binary gradient was set at $100 \%$ solvent A for $10 \mathrm{~min}$ then over 15 min a linear gradient to $68 \%$ mobile phase A, $32 \%$ mobile phase B and held at this composition for $10 \mathrm{~min}$. The conditions were again reset to $100 \%$ mobile phase A and 
allowed to equilibrate for $10 \mathrm{~min}$ before the next injection. Catechin identification was done by comparing the retention times of samples and standards under similar conditions. The standards used were Catechin (+) C, Epigallocatechin (-) EGC, Epicatechin (-) EC, Epigallocatechin gallate (-) EGCG and Epicatechin gallate (-) ECG. Total Catechins (TC) were expressed as a percentage by mass on a sample dry matter basis and given as a summation of individual Catechins as;

$$
\begin{gathered}
\% \text { Total Catechin }=[(\% \mathrm{EGC})+(\%+\mathrm{C})+(\% \mathrm{EC})+(\% \mathrm{EGCG}) \\
+(\% \mathrm{ECG})]
\end{gathered}
$$

Where;

ECG -Epicatechin gallate

EC -Epicatechin

EGCG -Epigallocatechin gallate

C- Catechin

\subsection{Statistical Analysis}

Data obtained were subjected to one-way Analysis of Variance (ANOVA) using the SAS 9.1 statistical software. The Significant Difference (LSD) test was used for mean separation where statistically significant differences were observed. Data were presented as a mean of the triplicate determinations \pm standard deviation (SD).

\section{Results and Discussion}

\subsection{Total Polyphenols}

As outlined in the procedure, polyphenols content of fresh tea leaves were determined during different supply of plain and molybdenum supplemented NPK fertilizers. From the results, each clone responded differently to fertilizer rates. On plain NPK fertilizers application, variety BBK 35 had higher percentage total polyphenol levels at an application rate of $300 \mathrm{Kg} \mathrm{NPK/HA} \mathrm{(figure} \mathrm{2).} \mathrm{The} \mathrm{reason} \mathrm{could} \mathrm{be} \mathrm{that}$ the optimum NPK fertilizer application rate specific to clone BBK 35 was $300 \mathrm{Kg}$ NPK/HA. At this rate BBK 35 was able to effectively utilize nutrients in the fertilizers applied which translated to the high levels of total polyphenols.

Table 1. Total polyphenols processed from clone BBK 35 grown in Monieri, Sotik Estate.

\begin{tabular}{ll}
\hline Fertilizer Rates (NPK/Ha) (kg) & Total Polyphenols (\%) \\
\hline 0 & $25.69^{\mathrm{bdec}} \pm 0.32$ \\
75 & $24.01^{\mathrm{f}} \pm 0.82$ \\
150 & $24.45^{\mathrm{fe}} \pm 0.38$ \\
225 & $24.77^{\mathrm{fde}} \pm 0.15$ \\
300 & $26.14^{\mathrm{bdac}} \pm 1.43$ \\
375 & $25.52^{\mathrm{dec}} \pm 0.25$ \\
$7 \mathrm{M}+0$ & $27.00^{\mathrm{ba}} \pm 1.17$ \\
$8 \mathrm{M}+75$ & $27.15^{\mathrm{a}} \pm 0.99$ \\
$9 \mathrm{M}+150$ & $26.20^{\mathrm{bdac}} \pm 1.16$ \\
$10 \mathrm{M}+225$ & $26.38^{\mathrm{bac}} \pm 0.13$ \\
$11 \mathrm{M}+300$ & $27.10^{\mathrm{ba}} \pm 0.97$ \\
$12 \mathrm{M}+375$ & $26.36^{\mathrm{bac}} \pm 0.99$ \\
Mean & 25.75 \\
LSD & 1.46 \\
CV & 3.33 \\
\hline
\end{tabular}

AHP $\mathrm{S} 15 / 10$ on the other hand was able to utilize the nutrients in fertilizers applied which lead to a higher percentage total polyphenols at an $75 \mathrm{Kg}$ NPK/HA and TRFK $6 / 8$ had a higher percentage total polyphenols levels at an application rate of $375 \mathrm{~kg} \mathrm{NPK} / \mathrm{HA}$ (table 2). Again, each clone had a different application rate which yields high levels of polyphenolic compounds.

On fertilizer supplemented with Molybdenum, all the three clones BBK 35, AHP S15/10 and TRFK 6/8 had one fertilizer application rate of $8 \mathrm{M}+75 \mathrm{Kg}$ NPK/HA (figure 3). Comparing those applied with plain NPK fertilizer (figure 2) and those supplemented with Molybdenum, those applied with NPK fertilizer supplemented with Molybdenum had a higher percentage polyphenols levels. Plants also use molybdenum to convert inorganic phosphorus into organic forms [19]. Molybdenum could have assisted in the conversion of Nitrogen, Phosphorus and Potassium nutrients to a form which could be easily utilized by the tea plants. TRFK 6/8 and AHP S15/10 were the most sensitive to the treatments with the highest $\mathrm{CV}$ of $4.70 \%$ and $4.43 \%$ respectively but BBK 35 was least sensitive response to treatment rates.

Table 2. Total polyphenols processed from clone AHP S15/10 grown in Mettarora, Sotik Estate.

\begin{tabular}{ll}
\hline Fertilizer Rates (Npk/Ha) (kg) & Total Polyphenols (\%) \\
\hline 0 & $23.73^{\mathrm{bac}} \pm 1.50$ \\
75 & $24.15^{\mathrm{ba}} \pm 1.62$ \\
150 & $23.65^{\mathrm{bc}} \pm 0.78$ \\
225 & $22.57^{\mathrm{dc}} \pm 1.15$ \\
300 & $24.01^{\mathrm{bac}} \pm 0.86$ \\
375 & $23.99^{\mathrm{bac}} \pm 0.84$ \\
$7 \mathrm{M}+0$ & $23.69^{\mathrm{bc}} \pm 1.01$ \\
$8 \mathrm{M}+75$ & $25.48^{\mathrm{a}} \pm 0.36$ \\
$9 \mathrm{M}+150$ & $21.63^{\mathrm{d}} \pm 1.37$ \\
$10 \mathrm{M}+225$ & $24.81^{\mathrm{ba}} \pm 0.64$ \\
$11 \mathrm{M}+300$ & $22.64^{\mathrm{dc}} \pm 0.95$ \\
$12 \mathrm{M}+375$ & $24.11^{\mathrm{bac}} \pm 0.74$ \\
Mean & 23.70 \\
LSD & 1.78 \\
CV & 4.43 \\
\hline
\end{tabular}

Table 3. Total polyphenols processed from clone TRFK 6/8 grown in Arroket, Sotik Estate.

\begin{tabular}{ll}
\hline Fertilizer Rates (NPK/Ha) & Total Polyphenols (\%) \\
\hline $0 \mathrm{~kg}$ & $25.57^{\mathrm{a}} \pm 0.54$ \\
$75 \mathrm{~kg}$ & $25.56^{\mathrm{a}} \pm 0.71$ \\
$150 \mathrm{~kg}$ & $26.23^{\mathrm{a}} \pm 1.09$ \\
$225 \mathrm{~kg}$ & $24.76^{\mathrm{a}} \pm 0.57$ \\
$300 \mathrm{~kg}$ & $26.31^{\mathrm{a}} \pm 1.18$ \\
$375 \mathrm{~kg}$ & $26.67^{\mathrm{a}} \pm 0.46$ \\
$7 \mathrm{M}+0 \mathrm{~kg}$ & $25.98^{\mathrm{a}} \pm 1.07$ \\
$8 \mathrm{M}+75 \mathrm{~kg}$ & $26.22^{\mathrm{a}} \pm 0.86$ \\
$9 \mathrm{M}+150 \mathrm{~kg}$ & $26.07^{\mathrm{a}} \pm 2.05$ \\
$10 \mathrm{M}+225 \mathrm{~kg}$ & $25.26^{\mathrm{a}} \pm 1.94$ \\
$11 \mathrm{M}+300 \mathrm{~kg}$ & $25.99^{\mathrm{a}} \pm 0.13$ \\
$12 \mathrm{M}+375 \mathrm{~kg}$ & $24.87^{\mathrm{a}} \pm 1.63$ \\
Mean & 25.90 \\
LSD & 2.05 \\
CV & 4.70 \\
\hline
\end{tabular}




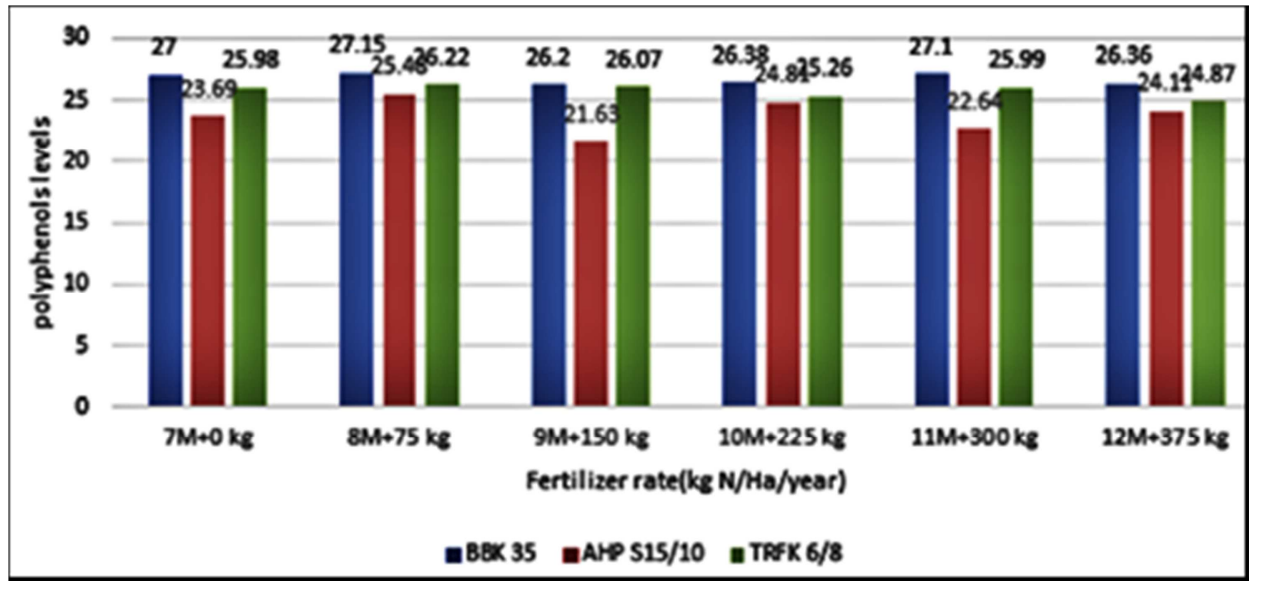

Figure 2. Effect of molybdenum supplemented NBK fertilizer on total polyphenols.

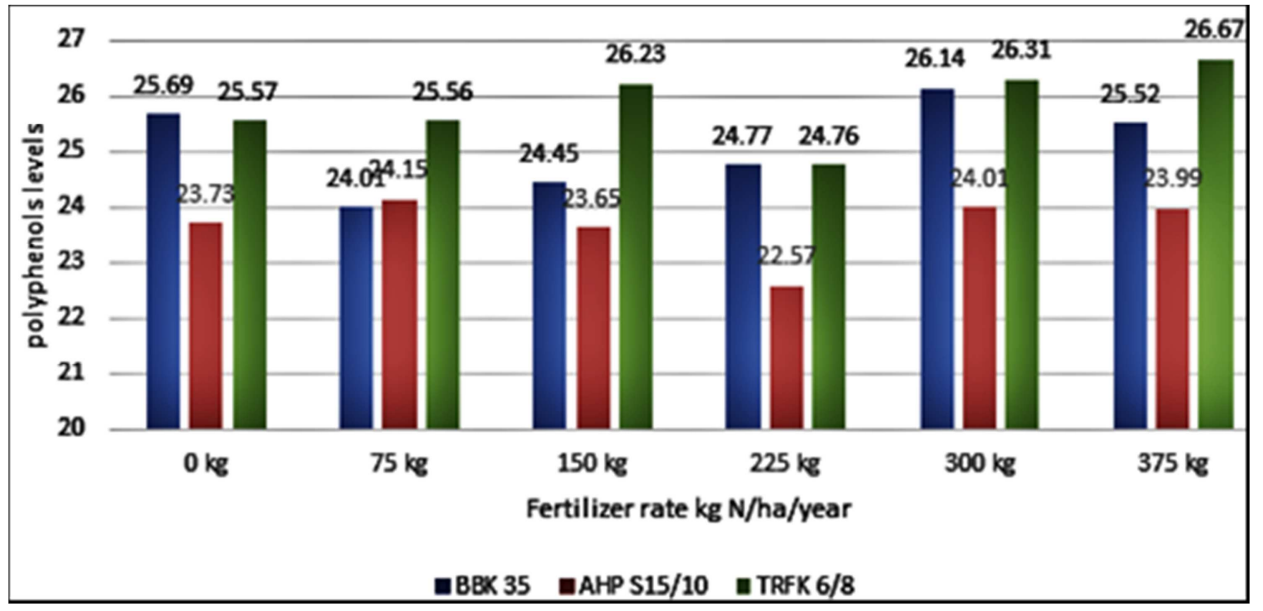

Figure 3. Effect of plain NPK fertilizer rates on polyphenols levels.

\subsection{Total Catechins}

The Catechins contents of tea leaves plucked from different treatments with different levels of nitrogen are presented in tables 4 and 5 .

The values in different treatments show the variations but were statistically non-significant. Similarly, treatments with molybdenum were at peak in pushes grown in presence of $10 \mathrm{M}+225 \mathrm{~kg} \mathrm{NPK} / \mathrm{HA}$ and the lowest amount was observed in treatment $7 \mathrm{M}+0 \mathrm{~kg} \mathrm{NPK} / \mathrm{HA}$ (figure 4). It has also found out that the quantity of total Catechins in samples treated with molybdenum were higher than those without molybdenum [4]. On NPK fertilizer not supplemented with Molybdenum, BBK 35 had a higher percentage total Catechins. From the results obtained, BBK 35 was the most sensitive to fertilizer rates applied. It was able to effectively utilize the nutrients in the fertilizers applied which was used in the synthesize of bio-chemicals hence higher levels of polyphenolic compounds On the samples applied with NPK fertilizers supplemented with Molybdenum, BBK 35 had higher levels of percentage total polyphenols. Molybdenum could have assisted in the conversion of nutrients in the NPK fertilizers applied hence the tea plants used the nutrients effectively. It has also been observed that there were higher polyphenolic levels in samples from tea plants applied with NPK fertilizers supplemented with Molybdenum [12]. BBK 35 and AHP S15/10 were the most sensitive to the treatments with the highest $\mathrm{CV}$ of $8.87 \%$ and $8.63 \%$ respectively but TRFK $6 / 8$ was least sensitive response to treatment rate with CV of $5.84 \%$.

Table 4. Total Catechins processed from clone BBK 35 grown in Monieri, Sotik Estate.

\begin{tabular}{ll}
\hline Fertilizer Rates $\mathbf{( N p k / H a ) ~} \mathbf{( k g})$ & Total Catechins $(\%)$ \\
\hline 0 & $14.42^{\mathrm{dc}} \pm 0.45$ \\
75 & $14.08^{\mathrm{d}} \pm 0.28$ \\
150 & $15.95^{\mathrm{bdc}} \pm 0.84$ \\
225 & $14.96^{\mathrm{dc}} \pm 0.85$ \\
300 & $15.95^{\mathrm{bdc}} \pm 1.03$ \\
375 & $15.11^{\mathrm{bdc}} \pm 1.47$ \\
$7 \mathrm{M}+0$ & $15.95^{\mathrm{bdc}} \pm 1.28$ \\
$8 \mathrm{M}+75$ & $16.05^{\mathrm{bdc}} \pm 0.37$ \\
$9 \mathrm{M}+150$ & $17.46^{\mathrm{ba}} \pm 2.83$ \\
$10 \mathrm{M}+225$ & $16.62^{\mathrm{bac}} \pm 2.58$ \\
$11 \mathrm{M}+300$ & $18.52^{\mathrm{a}} \pm 1.26$ \\
$12 \mathrm{M}+375$ & $18.59^{\mathrm{a}} \pm 0.52$ \\
$\mathrm{Mean}$ & 16.14 \\
LSD & 2.42 \\
CV & 8.87 \\
\hline
\end{tabular}




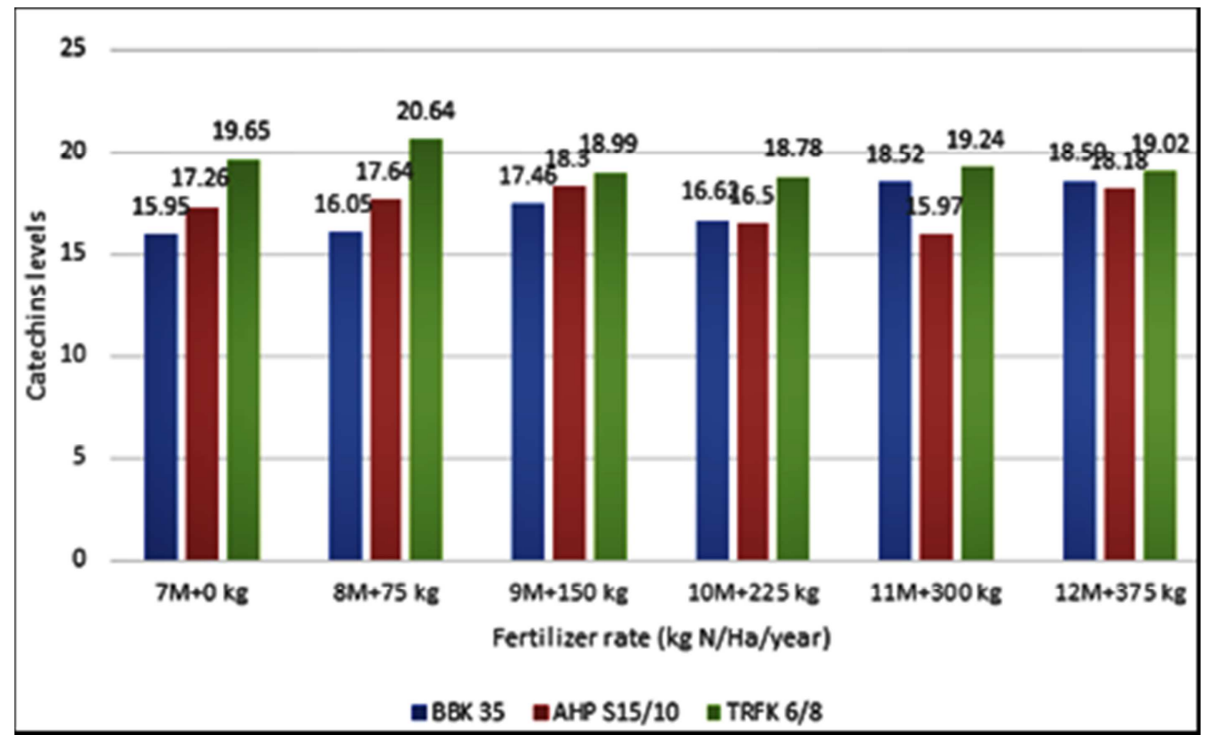

Figure 4. Effects of Molybdenum supplemented fertilizer rate on catechins levels.

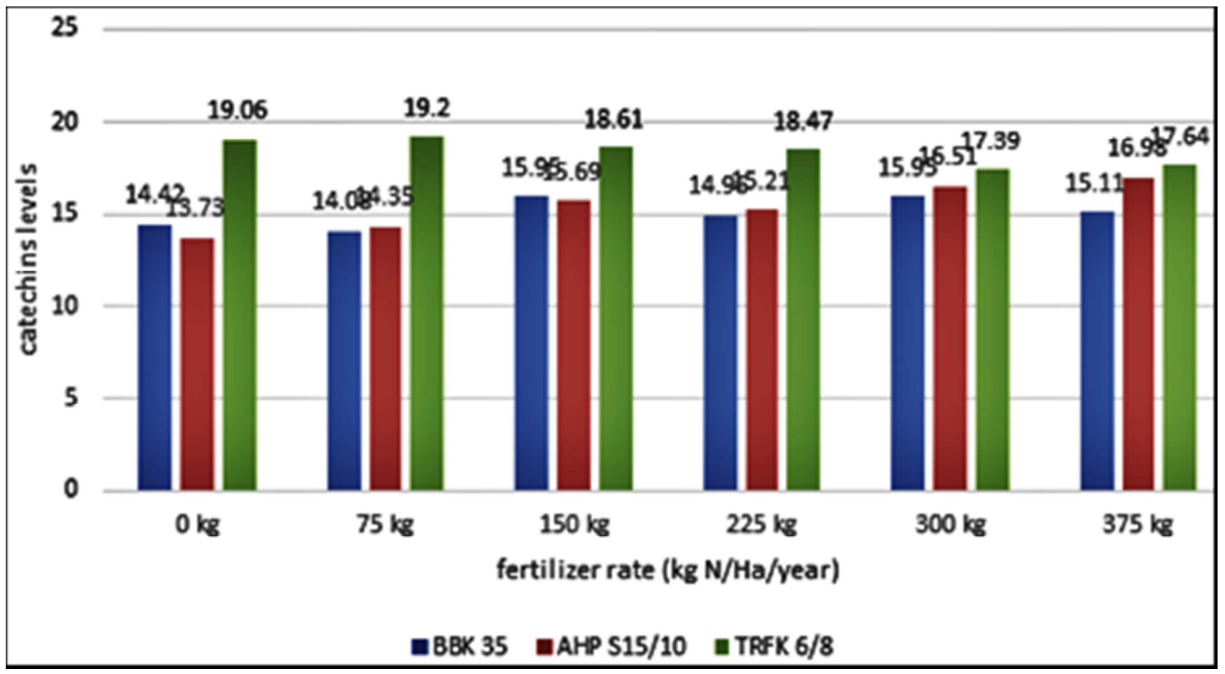

Figure 5. Effects of fertilizer rates on Catechins levels.

Table 5. Total catechins processed from clone AHP S15/10 grown in Mettarora, Sotik Estate.

\begin{tabular}{ll}
\hline Fertilizer Rates (Npk/Ha) $(\mathbf{k g})$ & Total Catechins $(\%)$ \\
\hline 0 & $13.73^{\mathrm{e}} \pm 1.77$ \\
75 & $14.35^{\mathrm{ed}} \pm 2.15$ \\
150 & $15.69^{\mathrm{ebdc}} \pm 0.23$ \\
225 & $15.21^{\mathrm{edc}} \pm 2.13$ \\
300 & $16.51^{\mathrm{bdac}} \pm 0.98$ \\
375 & $16.98^{\mathrm{bac}} \pm 1.66$ \\
$7 \mathrm{M}+0$ & $17.26^{\mathrm{bac}} \pm 0.65$ \\
$8 \mathrm{M}+75$ & $17.64^{\mathrm{ba}} \pm 0.97$ \\
$9 \mathrm{M}+150$ & $18.30^{\mathrm{a}} \pm 0.97$ \\
$10 \mathrm{M}+225$ & $16.50^{\mathrm{bdac}} \pm 1.44$ \\
$11 \mathrm{M}+300$ & $15.97^{\mathrm{ebdac}} \pm 1.06$ \\
$12 \mathrm{M}+375$ & $18.18^{\mathrm{a}} \pm 1.45$ \\
$\mathrm{M}$ an & 16.36 \\
LSD & 2.40 \\
CV & 8.63 \\
\hline
\end{tabular}

\section{Conclusion}

This research, therefore, concludes that with an increase in nitrogen fertilizer rates, biochemical are increased up to optimum levels where further increased rates does not lead to a decline in biochemical contents but rather makes tea farming unsustainable venture. it also concludes that tea bushes applied with NPK fertilizers supplemented with Molybdenum are rich in polyphenolic compounds as compared with those applied with plain NPK fertilizers.

From the above results, it can be concluded that application of $8 \mathrm{M}+75 \mathrm{Kg}$ NPK/HA fertilizers supplemented with Molybdenum could enhance the production as well as the polyphenolic content of made green tea of all the cultivars. It is recommended that NPK fertilizers supplemented with Molybdenum should be applied at the optimum levels since it boosts the biochemical contents in green tea and at the same time reduces production cost. 
Besides, other clones should also be subjected to the same study in order to get a more informed conclusion.

\section{Acknowledgements}

The authors are very grateful to the Kenya Agricultural and Livestock Research Organization-Tea Research Institute (KALRO-TRI) for granting us the opportunity to carry out the research project from their premises and allowing to use the equipment therein.

\section{List of Abbreviations}

$\begin{array}{ll}\text { CTC } & \text { Cut, Tear and Curl } \\ \text { EC } & \text { Epicatechin } \\ \text { ECG } & \text { Epicatechin Gallate } \\ \text { EGC } & \text { Epigallocatechin } \\ \text { EGCG } & \text { Epigallocatechin Gallate } \\ \text { HPLC } & \text { High Performance Liquid Chromatography } \\ & \text { Kenya Agricultural and Livestock Research } \\ \text { KALRO } & \text { Organization } \\ \text { NPK } & \text { Nitrogen, Phosphorus and Potassium } \\ \text { PPO } & \text { Polyphenol Oxidase Enzyme } \\ \text { TPVA } & \text { Tea Processing and Value Addition Programme } \\ \text { TRI } & \text { Tea Research Institute } \\ \text { TP } & \text { Total Polyphenols }\end{array}$

\section{References}

[1] J. Kitzes, M. Wackernagel, J. Loh, A. Peller, S. Goldfinger, D. Cheng, K. Tea. "Shrink and share: humanity's present and future Ecological Footprint". Philosophical Transactions of the Royal Society of London B: Biological Sciences, 2008, 363 (1491), 467-475.

[2] D. Bonheure, K. C. Willson. (1992). "Mineral nutrition and fertilizers in Tea. Springer, Dordrecht, 1992.

[3] ISO 14502-1-2005 "Reference, method for determination of polyphenolic compounds in green and black tea".

[4] M. Fazel, M. A. Sahari and M. Barzegar. Determination of Main Tea Seed Oil Antioxidants and Their Effects on Common Kilka Oil. International Food Research Journal, (2008) 15, 209-217

[5] K. O. George, T. Kinyanjui, J. Wanyoko, O. K. Moseti, and F. Wachira. Extraction and Analysis of Tea (Camellia sinensis) Seed Oil from Different Clones in Kenya. African Journal of Biotechnology, (2013) 12, 841-846. [7]

[6] Yahaya, L. E., Wang, Y., Sun, D., Chen, H., Qian, L. and Xu,
P. (2011) Fatty Acid Composition and Antioxidant Activity of Tea (Camellia sinensis L.) Seed Oil Extracted by Optimized Supercritical Carbon Dioxide. International Journal of Molecular Science, 12, 7708-7719.

[7] C. P. Lee and G. C. Yen. Antioxidant Activity and Bioactive Compounds of Tea Seed (Camellia oleifera Abel.) Oil. Journal of Agricultural and Food Chemistry, 2006, 54, 779-784.

[8] P. O. Owuor. "High rates of nitrogen on tea. Effects of Fertilizers on Tea Yields and Quality". 2001, Preventive medicine, 21 (3), 334-350.

[9] M. Obanda, P. O. Owuor, S. J. Taylor. "Flavanol composition and caffeine content of green leaf as quality potential indicators of Kenyan black teas". Journal of the Science of Food and Agriculture, 1997, 74 (2), 209-215.

[10] A. Gulati. "Tea Manufacture". Science of Tea Technology, 2013, 401.

[11] L. Bravo. "Polyphenols: chemistry, dietary sources, metabolism, and nutritional significance". Nutrition reviews, 1998, 56 (11), 317-333.

[12] D. G. Nagle, D. Ferreira, Y. D. Zhou. "Epigallocatechin-3gallate (EGCG): chemical and biomedical perspectives". Phytochemistry, 20065, 67 (17), 1849-1855.

[13] S. Ramkumara, P. S. kumarb, J. Gandhi, A. S. Geethac, P. Mohankumard, V. K. Gopalakrishnan. Biochemical and molecular analysis of Camellia sinensis (L.) O. Kuntze tea from the selected $\mathrm{P} / 11 / 15$ clone. Journal of Genetic Engineering and Biotechnology. (2016) 14, 69-75

[14] X. Ruan,. Wu, Härdter. "Effects of potassium and magnesium nutrition on the quality components of different types of tea". Journal of the Science of Food and Agriculture, 1999, 79 (1), 47-52.

[15] H. N. Graham. Green tea composition, consumption, and polyphenol chemistry. Preventive medicine, 1992, 21 (3), 334350 .

[16] Y. Hara. Green tea: health benefits and applications. CRC press 2001.

[17] B. N. Kaiser, K. L. Gridley, B. J. Ngaire, T. Phillips, S. D. Tyerman. "The Role of Molybdenum in Agricultural Plant Production". Annals of Botany, 2005, 96 (5), 745-754.

[18] K. O. George, T. Kinyanjui, J. Wanyoko, O. K. Moseti, and F. Wachira. Quantitation of the Total Catechin Content in Oils Extracted from Seeds of Selected Tea (Camellia sinensis (L) O. Kuntze, Theaceae) Clones by RP-HPLC. American Journal of Plant Sciences, 2015, 6, 1080-1089

[19] F. M. Ngure, J. K. Wanyoko, S. M. Mahungu, and A. A. Shitandi. Catechins Depletion Patterns in Relation to Theaflavin and Thearubigins Formation. Food Chemistry, 115, 2009, 8-14. 